\title{
MESA 3: RELATORIA
}

CLÁUDIO LUÍS RIBEIRO ${ }^{1}$

PUCP

\section{PARTE I}

O evento abre exibindo um vídeo com o aluno peruano José Luís Antarki, onde ele diz que os indígenas estão se globalizando, ou seja, ingressando no grande círculo social do mundo, e que, apesar deste processo, não perdem a essência. Diz que escutou a voz do mar lhe dizendo que ele é filho da Pachamama. Afirma, também, que sua experiência na cidade serviu para saber o que não lhe convém. Abandonou o programa de estudos na Universidade Federal do Rio Grande do Sul (UFRGS).

O vídeo mostra o que pode acontecer com uma pessoa inserida em meio diferente, longe de seu domínio, família e hábitos. Foi uma tônica do encontro o despreparo da universidade (em geral) para receber quotistas, sobretudo no setor de acompanhamento/acolhimento, o que em boa parte das vezes gera desconforto e ansiedade nos alunos.

- Primeira intervenção: Karen Bruck - Técnica em Educação, representante da Coordenadoria de Acompanhamento do Programa de Ações Afirmativas da UFRGS. Karen lembra que o Programa existe desde 2008. Frisa que, na verdade, ele é de responsabilidade de todos. Também diz

\footnotetext{
${ }^{1}$ Bacharel em Música pela Universidade Federal do Rio Grande do Sul (1982). Mestre em Música pela University of Denver (2008 - USA). Doutorando em Antropologia junto à Pontifícia Universidade Católica do Peru (PUCP), com pesquisa sobre xamanismo da costa norte peruana. E-mail: maestrocribeiro@gmail.com.
} 
que a UFRGS é uma das poucas universidades que criaram um núcleo específico de gestão das políticas afirmativas. Salienta que a Região Sul está tomando a dianteira no sentido de criar um fórum para debater a sequência do Programa, sua adequação e visibilidade em longo prazo. Também destaca que a diversidade ainda é um "problema" que requer reflexão e propósitos de enfrentamento mais claros.

- Segunda intervenção: Prof. José Rivair Macedo, do Programa de PósGraduação em História (PPGHist/UFRGS). Ressalta que participar no evento fortalece o programa de História da UFRGS. Lembra que nos anos 90 foi o primeiro professor a orientar um aluno negro (Hilton Costa, hoje professor no Paraná). Macedo destaca que a UFRGS tem perdido alunos quotistas para a Pontifícia Universidade Católica do Rio Grande do Sul (PUCRS) e outras universidades privadas, pois o departamento alega que os assuntos que estes alunos trazem não interessam ao programa da unidade. Nesta direção, considera que o "racismo epistemológico" é uma realidade que precisa ser enfrentada e combatida. É preciso estar atento ao empoderamento do saber.

- Terceira Intervenção: Prof. Danilo Braga (kaingang), licenciado em Educação pela Universidade Regional do Noroeste do Estado do Rio Grande do Sul - Unijuí, em 1995. De 2001 a 2005 foi cacique da TI Ligeiro (Charrua/Tapejara), a primeira aldeia que o Serviço de Proteção ao Índio (SPI) administrou, em 1911. Desde 1999 é professor na TI Serrinha (Ronda Alta). É mestre em História pela UFRGS. Sua dissertação é um memorial de sua vida e trajetória até a chegada à universidade. Luta para que haja Ensino Fundamental completo em todas as aldeias. Com humor irônico, Danilo comenta a respeito de seu cotidiano universitário: "o pensamento europeu não conseguia entrar na minha cabeça". Agora tem como meta ingressar no doutorado. Ressalta que foi um grande desafio chegar "até aqui" e que quer prosseguir na caminhada.

- Quarta intervenção: Profa. Maria Aparecida Bergamaschi, coordenadora do Programa de Pós-Graduação da Faculdade de Educação (PPGEdu/FACED) da UFRGS. A professora lembra que o programa tem mais de quarenta anos e conta com setenta professores, tendo desde o 
início dos anos 80 recebido alunos negros. Acentua que a qualificação do corpo docente no Exterior proporcionou contato com colegas de outros países, o que trouxe abertura ao acolhimento do programa por parte da UFRGS. Bergamaschi sublinha que dois estudantes kaingang já concluíram o mestrado e dois cursam este programa atualmente, tendo um deles recebido bolsa da Fundação Ford. Enfatiza que o exame de idiomas para ingresso na pós-graduação ainda é barreira a ser discutida. Também alerta para o fato de que o valor atual da bolsa/MEC (R\$1.500) torna a permanência do aluno muito difícil. $O$ acolhimento é falho: um exemplo é o tempo que os alunos necessitam para se adaptar ao ritmo acadêmico e ao cotidiano humano, o que não é levado em conta pelo programa de ações como deveria. Um fator positivo é a ampliação que as metodologias obtiveram com a chegada dos saberes tradicionais. Para a professora, a Universidade ganhou com a escrita desocidentalizada dos Kaingang, rica em imagens e emoção.

- Quinta intervenção: Prof. Zaqueu Claudino (“Kej”), kaingang, coordenador do Ensino Médio Politécnico Kaingang, diretor da Escola Indigena da Aldeia Guarita, que conta hoje com 217 alunos. O professor recorda que foi uma agente da Fundação Nacional do Índio (FUNAI) que o incentivou a estudar. Hoje Zaqueu é mestre em Educação pela UFRGS. Estudava à noite e durante o dia vendia artesanato na Redenção para fazer frente aos gastos. Diz que a educação faz parte da elite e que para o indígena é difícil ter acesso a ela. Zaqueu aborda a questão da relação social: "na aldeia os indígenas recebem o saber dos antigos pela oralidade; na academia, os 'pajés' (professores) transmitem o conhecimento 'científico'", o que significa, na prática, outra forma de comunicação que requer tempo de elaboração por parte daquele que chega ao novo ambiente. Zaqueu salienta que foi importante o programa pré-acadêmico da Faculdade de Educação (FACED/UFRGS), pois possibilitou que seguisse no curso. Também diz que "não adianta ter política de ações afirmativas se não houver política de acolhimento e sequência no estudo. As desistências ocorrem justamente por causa disso". Esclarece que é preciso repensar a política de atendimento aos alunos oriundos dos coletivos tradicionais: "é um choque sair da aldeia e vir para a cidade de pedra". O tema que desenvolveu no mestrado aborda 
a desconstrução do pensamento ocidental integralista, que visava compelir o índio à sociedade "ordem e progresso". Também questiona Zaqueu: "fazer pedagogia aos irmãos indígenas por quê?!". Para o professor kaingang, este é o núcleo da questão - é preciso trabalhar com os alunos, mostrar-lhes os diversos conhecimentos (ocidentais), mas sem esquecer a tradição e a essência indígena. Pergunta sobre a Casa do Estudante: Será que também neste local há um acompanhamento ao aluno indígena? Por fim, Zaqueu descreve um fragmento da cosmologia de seu povo: "o conhecimento é transmitido junto ao fogo; deitar no solo ajuda a absorver mais o conhecimento pelo contato com a mãe-terra”.

- Sexta intervenção: Prof. Bruno Ferreira (kaingang), morador da Aldeia Guarita. Trabalha no Instituto Indígena Inhacorá, onde ministra aulas de História e Direito Indígena. Faz questão de ressaltar que foi criado pela bisavó e só dominava o idioma kaingang. O maior desafio foi ser alfabetizado em português. Neste processo, teve de superar várias reprovações e dificuldades de toda ordem. Estudou Letras e se formou em História. Teve oportunidade de ficar um mês na Universidade Estadual de Campinas (Unicamp), onde foi vítima de segregação e preconceito. Seu projeto de mestrado foi um questionamento sobre a formação do educador e sua missão, projeto que foi acolhido pelo PPGEdu/FACED/UFRGS. Com a EST (Escola de Teologia, Morro do Espelho, São Leopoldo) conseguiu moradia. Em seu percurso de estudo sofreu assédio moral, como relata: "eram expressões do tipo 'entraste aqui porque é índio' ou 'lugar de índio é no mato'”. Em sua opinião, a universidade ainda não consegue acolher o conhecimento indígena. $\mathrm{E}$ conclui: "o mais difícil na politica das ações afirmativas é manter o aluno indígena como indígena. Os indígenas têm voz!".

\section{PARTE II}

- Primeira intervenção: Profa. Liliana Pessarino, do PPGEdu/UFRGS. Reflete sobre inclusão de pessoas com deficiência no programa de pósgraduação. Conforme a docente, os portadores de deficiências passam por um longo processo de dificuldades que obstaculizam acesso, 
mobilidade e acolhimento junto à Universidade. Liliana apresenta dados do MEC: em 2013, a Educação Básica no Brasil contava com 843.000 alunos com alguma forma de deficiência; destes, apenas 48.000 chegaram ao Ensino Médio. Na opinião da professora, este afunilamento é um sintoma do despreparo do sistema educacional no atendimento aos portadores de deficiências. Hoje, nas universidades públicas brasileiras, há 9.000 alunos com algum tipo de deficiência. Liliana é explícita: "Na UFRGS, pessoas com deficiência não participam das ações afirmativas. Um dos maiores problemas é a falta de instrumentos de comunicação do aluno deficiente com a UFRGS". Como dado positivo, Liliana ressalta que o PPGEdu formou a primeira pessoa surda e a primeira pessoa cega em meados dos anos 2000. A docente sugere criar mecanismos administrativos e formação funcional (humanística) para implementar uma política de ações realmente eficiente, e defende a ideia de que a política de ações afirmativas tem de incluir, também, os portadores de deficiência.

- Segunda intervenção: Prof. José Carlos Anjos, do Programa de PósGraduação em Sociologia (PPGS/UFRGS). Como axioma fundamental, o professor é claro: "os programas de políticas afirmativas estão despreparados para a função que deveriam fazer". A seguir, analisa quatro grandes problemas do atual sistema, assim como aponta maneiras de melhorar a política de ações:

a) É indispensável criar comitês de orientação interdisciplinares; estamos transformando diferença em erro, erro em reprovação, reprovação em exclusão. Urge transformar a diferença em processo de aprendizado e permitir que o aluno receba atendimento naquilo que é seu objetivo;

b) É preciso que o processo de diversidade seja realmente assumido e que os alunos sejam recebidos de forma inteira;

c) É necessário flexibilizar o processo de prazos; os alunos diferenciados precisam de mais tempo para que produzam efeitos nos programas e nas próprias políticas afirmativas;

d) É fundamental o engajamento institucional, através do posicionamento das unidades, e não apenas do departamento "a" ou "b". 
Por fim, o docente afirma que, numa categorização étnica, a definição categorial tem de ser "negro" e não "preto" ou "pardo".

- Terceira intervenção: Felipe Mianes, ex-aluno do PPGEdu/UFRGS, deficiente visual. Atualmente Felipe faz pós-doutoramento na ULBRA. No PPGEDU/UFRGS, Felipe obteve os títulos de Mestre e Doutor. "Tive muita dificuldade hoje para acessar o Campus do Vale", relata, ao referir sobre sua vinda para participar do debate. Felipe faz uma crítica à dificuldade que os portadores de deficiência encontram na relação com as ferramentas do curso na UFRGS. Há carências de livros especiais, computador adaptado, etc.. Lembra que solicitou um computador ao ingressar no programa de doutorado. "Quando terminei o curso o computador ainda não havia sido adquirido. A UFRGS faz política para deficientes e não com os deficientes". Os prazos não são cumpridos e os atendimentos são sempre pessoais, ou seja, dependem de boa vontade e não configuram compromissos administrativos ou institucionais. Sendo os serviços maus, é preciso pensar como fazer a inclusão das pessoas portadores de deficiências. As políticas afirmativas tem de ser também estendidas às pessoas deficientes. "Este é um problema de todos nós. Um dia todos serão deficientes", conclui Felipe.

- Quarta intervenção: Prof. Marcos Soares Morais, docente do Ensino Fundamental em Eldorado do Sul. Graduou-se em História e tem Especialização e Mestrado em Educação pelo PPGEDU/UFRGS. Marcos abre sua intervenção abordando o problema de aceitação do deficiente no meio social; e lança uma indagação: "será preciso andar com um crachá dizendo 'negro', 'indígena', 'deficiente?’”

Deixa claro que não conhece nenhuma ação afirmativa para deficientes, na UFRGS. Ressalta que não se deve rotular as pessoas deficientes e que é preciso criar reais condições de atender institucionalmente os deficientes. Enfatiza que há preconceito com o quotista. "Ações afirmativas devem ser pensadas para o todo e não como um ato de caridade". Marcos finaliza sua participação com uma reflexão: "As melhores coisas da vida se faz no escuro ou de olho fechado". 
Recebido em: 14/11/2015 * Aprovado em: 14/12/2015 * Publicado em: 31/12/2015 